\title{
Teaching Writing on a Reading-Based Task — A Comparative Study
}

\author{
Shirley Shao
}

\begin{abstract}
This research will explore the effectiveness of a writing course by comparing two different English as foreign language (EFL) teaching procedures. It reviews previous researches on how reading affects writing as an input instrument, drawing the suggestions to guide reading-based (reading as a task) teaching in writing class. A comparative teaching experiment will be carried out in order to examine the practicality of reading-based task. Two separated groups of students will be involved in the experiment, and they will be taught by traditional writing pattern and reading-based task separately. With the duration of 4 weeks, evaluation questions are distributed to the students, followed with analysis of the results and focus group interviews within the group. The results to be revealed could provide referential ideas for current EFL writing teachers.
\end{abstract}

Index Terms-Task-based teaching, IELTS writing, international school, China.

\section{INTRODUCTION}

\section{A. A Brief Historical Backdrop}

Reading and writing are interdependent language skills. Reading in a foreign or a second language (henceforth, L2) has been emphasized as one of the most important skills to be acquired by learners since the mastery of the skill has been proven to be essential for the development of language proficiency [1].

Positive impacts of extensive reading are reported in other areas of language development, especially in writing [2]. Also, it has been showed students with reading difficulties hardly perform well in their writing [3]. As a way of learning output activity, writing reinforces the acquired knowledge for second language learners when students could internalize what have learned in class. Hence, the teaching of writing serves as an important way for learning [4].

In traditional writing class, the questions are set separately with provided vocabulary and sentence drills. However, the independent writing usually demotivates students as the pattern is rather fixed, and it is difficult for students to find detailed information and evidence to support their ideas. Instead, integrated writing with well-designed tasks could tap students potential and inspiration from the reading texts [5].

\section{B. Contemporary Context}

Most students are struggling with writing. According to the statistics in 2017 in an academic IELTS writing, the

Manuscript received June 20, 2018; revised September 13, 2018.

Shirley Shao is with the International department of Hunan Normal University attached high school, Changsha, China (e-mail: huijuanuk@163.com). overall band wiring score is 5.3, which ranks the lowest among the four language skills. The difficulty of English writing for second language learners not only lies in the usage of appropriate language, but also the perception of thinking in English. For students in high school, they lack the awareness to build their thinking block because of heavy study load, and also English education in most secondary schools emphasize on traditional language skills, such as word memorization, grammar drills and sentence patterns. Chinese students are normally weak in their language output (writing and speaking), which are essential in their later study and career. Hence, the research for innovation and improvement in writing class should be underlined in today's English class.

\section{Main Purpose of the Research}

The integration of writing and reading has been proposed as interactive way in language learning. Comprehensible input in intensive reading could benefit students for injecting wide range of vocabulary and sentence patterns. Also, the natural flow of language would be reinforced time by time when students get familiar with the textual features, including structure, styles and ideas presented. The research is aimed at helping students build their "writing pool" by employing the reading material in class. Beyond the important skill, students are expected to form the habit of absorbing essence from intensive reading and consciously integrating into their own writing.

\section{Statement of the Research Question}

The research are designed to explore the following question:

1) Is there significant difference in students' work between writing with reading-based context or without?

2) How does reading-based context affect students' writing assignment?

\section{METHOD}

\section{A. Design}

Four weeks teaching session: The research involves four weeks for the teacher to implement a reading-based writing class. The period could cover 8 different writing topics with comprehensible reading material for each topic. Students are asked to establish their own writing portfolio for tracking.

\section{1) Traditional writing teaching plan}

Lesson content: Writing topic of educational issues

Anticipated Problems: Students may have difficulty in expanding ideas and using relative vocabulary

Objective(s): 
At the end of the lesson, the students are able to:

- describe educational problems with accurate words and flexible sentence patterns

- figure out reasons and suggestions behind the environmental issues

Stage 1 warming-up (5 mins)

Present several pictures concerned with educational trends

Stage 2 Vocabulary building (10 mins)

Learn other important vocabulary about educational issues

Stage 3 sentence translation (15 mins)

Complete five sentence translation using the vocabulary that students have learned

Stage 4 exercise (10 mins)

Variable vocabulary and sentence exercise

Stage 5 question analysis (10 mins)

Analysis the writing questions: make accurate response and appropriate structure

Stage 6 define ideas (15 mins)

Write a outline which contains all topic sentences in each paragraph

Stage 7 topic expanding (15 mins)

Discuss other questions of educational problems and reinforce the thinking mode

Stage 8 summary ( 5 mins)

General Summary of the lesson

Homework: Complete the writing essay according to the writing outline in class

\section{2) Reading-based writing teaching plan}

Lesson content: Writing topic of educational issues

Anticipated Problems: Students may have difficulty in expanding ideas and using relative vocabulary

Objective(s):

At the end of the lesson, the students are able to:

- describe educational problems with accurate words and flexible sentence patterns

- figure out reasons and suggestions behind the educational issues

Stage 1 warming-up (5 mins)

Present several pictures concerned with educational trends

Stage 2 reading task (10 mins)

Scan the reading passage and summarize the main idea; Define important vocabulary

Stage 3 reading task (15 mins)

Check the ideas in the passage and discuss whether students agree with them

Stage 4 discussion (10 mins)

Extract key information and synthesize with understanding

stage 5 Review of the text (10 mins)

Complete a mind map according to the reading text

Stage 6 Vocabulary expanding (15 mins)

Stage 7 Complex sentence analysis (15 mins)

Analyze sentence structure and imitation exercise

Stage 8 Summary (5 mins)

General Summary of the lesson

Homework: Complete the writing essay according to the mind map in class

Research information about other kinds of environmental pollution after class

\section{B. Participants}

Two groups of students with 16 each: Students all from international department in Hunan Normal University attached high school (Changsha, Hunan). As these students are intended to study abroad, English education has to be prioritized. Most students will attend the standard test (TOEFL or IELTS) after they are in grade 11. According to latest test result, their English language level is between C2-B1 (CEFR), and in speaking and writing, they have lower grades.

This research involves grade 11 students, dividing them randomly into two groups, each with 16 students. Group 1 adopts traditional writing teaching method, i.e. writing sample or pattern analysis and practice; group 2 will implement a reading-based writing procedure.

\section{1) Instruments}

Evaluation questions \& focus group interview: After four weeks, students will be asked to complete a writing task. Their performance will be marked according to the standardized criteria concerned with task response, grammar accuracy, sentence and vocabulary variety and coherence. Focus interview will be involved with students at different language level, forming a group with 4-6 students. They are required to answer questions about how far they could benefit from the lesson, as well as how do they feel about the structured questions after they attend the class. The questions are followed as:

\section{a) Evaluation question}

In some countries there is not enough recycling of waste materials (eg. Paper, glass and cans.) What are the reasons and solutions?

Students' work will be evaluated based on the accuracy and variety of vocabulary, sentence structure, textual coherence and flow of ideas.

\section{b) Focus group interview questions}

1) What do you learn in the class?

2) How helpful it is for your writing?

3) Are you interested in what you have learned in the class?

4) What would you like to change about the lesson?

5) Do you feel active to learn in the class?

6) Is there any difficulty for you to write after class?

\section{DISCUSSION}

\section{A. Analysis of Students' Essay}

After the distribution of the writing questions, students' essays are collected. In the first evaluation stage, all the 32 students' essays in group1 and group 2 are marked. According to the writing criterion of IELTS, students' essays are examined in terms of organization, content and language with equal given weight. After four weeks' tutorial, students in group 1 (reading-based class) achieve greater improvement with 56.2\% matching band 5.5, while the figure is only $37.5 \%$ in group 1 . The overall score is 5.156 and 5.406 for students in group 1 and group 2 respectively (see Table I-V).

Specifically, the traditional teaching of writing, though provides students a writing pattern that facilitates well-fund structure, hardly achieve the flexibility. Students are trapped 
in a fixed thinking mode which only the teacher offered in class. As a result, they hardly can provide persuasive evidences in their own way. Or even, some students make up statistic or personal example in order to meet the word count.

\begin{tabular}{|c|c|c|}
\hline Group/score & Group 1 & Group 2 \\
\hline above 5.5 & $6.25 \%$ & $18.8 \%$ \\
\hline 5.5 & $37.5 \%$ & $56.2 \%$ \\
\hline 5 & $37.5 \%$ & $12.5 \%$ \\
\hline Below 5 & $18.75 \%$ & $12.5 \%$ \\
\hline \multicolumn{3}{|c|}{ TABLE II: OVERALL SCORE } \\
\hline & Mean & Standard deviation \\
\hline roup 1 & 5.156 & 0.532 \\
\hline Sroup 2 & 5.406 & 0.675 \\
\hline \multicolumn{3}{|c|}{ TABLE III: ORGANIZATION } \\
\hline & Mean & Standard deviation \\
\hline Group 1 & 5.337 & 0.362 \\
\hline Group 2 & 5.386 & 0.383 \\
\hline \multicolumn{3}{|c|}{ TABLE IV: CONTENT } \\
\hline & Mean & Standard deviation \\
\hline Group 1 & 5.082 & 0.651 \\
\hline Group 2 & 5.487 & 0.483 \\
\hline \multicolumn{3}{|c|}{ TABLE V: LANGUAGE USE } \\
\hline & Mean & Standard deviation \\
\hline Group 1 & 4.989 & 0.672 \\
\hline Group 2 & 5.345 & 0.587 \\
\hline
\end{tabular}

The following is one of the example after students having attended the traditional writing class:

"For example, when you bought a souvenir for your friend, maybe your friend will ask you the information about souvenir and you will tell his friends. So more and more people will know some culture, it will make this kind of countries proud of themselves."

In order to prove the idea "international tourism could help the host countries bring their culture to all over the world", the writer use personal examples to replace commonality, which is likely to make the argumentation weak.

The example demonstrates that students cannot draw on essence to build their own ideas with creativity. Also, they learned the vocabulary without textual context, which largely affects the effectiveness of the word choice. See the work of students in the other group, one of them has utilized word chunk in the reading material with the similar context in the question: "I believe that such details should be controlled and strictly censored. Obviously, the extensive media coverage of crime does great damage to the society. One of the adverse impact is the growing juvenile delinquency." To a larger extent, students who attend the reading-based writing class show a better adaptation and flexibility in the use of new vocabulary: "It is a undeniable fact that those TV, computers and videodisk indeed enliven the classes and increase the efficiency in class as they can record the process of learning or give a clear outline of the course when presenting on the screen." (the underlined words are from reading material)

In terms of content, students differentiate each other in ideas, as well as supporting details. However, students in traditional writing class reveal a bigger individual difference, which means they mainly depend on their original mental resource. What they produce derive from their input of reading, listening or their own life experience. When they write, they need to search and reorganize the information, probably stored long time ago, in their mind. With the restriction of time, some of them are liable for mismatch of ideas and supporting details, which may lead their writing off-topic. As the ideas goes "young people who likes to eat fast food may not be physically developed," the author further develop by adding "that is, teenagers should eat a few amount of vegetables and fruit." Obviously, the author misunderstands the contextual relationship. This is largely due to the fact that they have not formed a habit of analyzing other argumentative text before they write. Also, the details could lack the reliability or further explanation in students' writing.

In contrast, students in the other group are more capable in using pervasive details for they are provided with reliable source from the reading. Students with better integration skills show natural and flexible application of the information provided as argumentation: "Technology is not a panacea, the active class depends on how teachers attract students' attention. Although technology can have some positive impacts on education, it cannot come at the expense of replacing teachers."

Once they finish their writing, the material could also be internalized in their metal pool.

Finally comes to the discussion of organization, students in traditional class generally performs well as they are required to write an outline in class. Most of them obey the structure of writing template, so it is rather clear and easy to follow the paragraph. The other group of students may not use the fixed pattern in their writing, but with paragraph based on divided ideas. Compared with the other two aspects, organization in IELTS is quicker and easier to learn. After the reinforcement of two essays by students, most of them could command the rules of structure.

\section{B. Students' Response}

The focus interview group is made up 6 group members with each 2 standing for outperformed, intermediate and underperformed students. The outperformed students benefit the most from reading-based class. They all respond that the reading material in class deepen their insights and expand the scope of learning of the topic. Also the class activates the their interest in current issues and real-life examples as the teacher presents news review in the text. In contrast, the outperformed students in group 1 say the class tends to be more grammar-centered with fixed pattern, they could learn more vocabulary but cannot exercise their thinking.

For the two intermediate students, they are ready to do the reading task in order to find the information for writing. Also, they feel that the learning atmosphere is better as more time is allowed for discussion and interaction in groups. The ideas and expressions for outperformed students also inspire these students to think aloud. Meanwhile, they appreciate the time for vocabulary building.

But as for the underperformed students, the suggested time for reading seems inadequate for them. They fall behind as 
they are weak in summary of main ideas and scanning for specific information. Rather, they depends on teacher to organize ideas and produce English expressions. They also respond that they hope teacher could slow down the pace of teaching in a direct way and ask less open questions. Hence, they like to be instilled with vocabulary, sentence translation and ideas presented in traditional writing class.

\section{Suggestion and Limitations}

The study has discussed potential teaching conduct of two possible writing class based on different teaching philosophy. By analyzing the students' essay, a conclusion can be made that students are generally perform better in generating ideas and improving language when reading-based tasks are presented in a writing class. Also, students with different English proficiency have distinct adaptability to the teaching method. Reading-based teaching is liable to benefit advanced students more.

The study has several important implications for teachers. First, the output of writing largely depends on reading material absorbed beforehand. If the teacher could provide valuable and inspiring readings concerning with writing topic students will gain more desirable outcomes, which are revealed in language use, including word choice, collocation and sentence patterns, as well as supporting evidence and details. Moreover, in a controlled class with limited time, it is advisable for teachers to select suitable reading material that would accommodate the overall students' reading competence.

Admittedly, it is obviously a pilot study on a small scale of students, and it only serves for initial trial for teaching practice. The applicable procedures should be explored with more intricate steps. Moreover, the evaluation should be designed in a quantitive way with data analyzed in order to ensure the validity.

\section{APPENDIX TOPIC-BASED READING MATERIAL}

\section{Videodisk or Teacher: Who Wins in Class}

For a generation of young people have tuned into video images for entertainment and recreation, videodisk players and huge-screen televisions in school seem as natural as sunlight and windowpanes. But with national reading scores continuing to slide and few scientific studies on the effectiveness of video-assisted teaching, educators are divided on whether wiring teachers to higher technologies will help students learn. Late last month, college board officials announced that the verbal skills of college-bound high school seniors who recently took the scholastic aptitude test had dropped to their lowest level in decade. Robert G. Cameron, executive director of research and development for the board, a non-profit education services company, said the decline was further evidence of an erosion of reading skills in an age in which electronics deliver much of the country's information. Jeanne Chall, a Havard university professor of education, said careful use of sound and images in teaching could enliven a subject, but none of it should come at the expense of reading. " if the time comes when we find ourselves spending a great deal of time listening and looking has at images, we will become a very weak nation in language and literacy," Dr. Chall said, " the only way to read it is to read a great deal."

In round rock, Tex, about 20 miles north of Austin, the videodisk system the state is considering has been extensively used in pilot program - to the delight of teachers there, " teachers enjoyed using it and students responded well to it," said Virginia Woods, science coordinator for the 20,000-student school system. She said the program actually stimulated students' desire to read. "students get excited after having seen the disks and desire to read. Mrs. Woods said. But she emphasized that videodisks were like any other teaching tool. "It is something else to use." She said. "some students do better than some others with it." Virtually everyone interviewed underscored this point: in the total curriculum, videodisks should complement, not displace, textbooks. "There is no one source of information that you give the children," said Lyn Chan, a sixth-grade teacher at skyline elementary school in San Francisco, who uses both standard and electronic textbooks. Videodisk technology is "not a panacea," Mrs. Chan said.

For the last several years she has been using videodisks as part of a pilot program and has been impressed by the way they capture and hold students' attention. She said videodisk had several advantages for teachers. First, they are simple to operate; Mrs. Chan said she has taught teachers how to use them in less than five minutes. Using remote control, a teacher can order a disk player to find and display still or moving images of a particular subject. The search and display process takes a few seconds, whereas finding a specific image on videotape can take several minutes of winding and rewinding, she said. Also with conventional films, and sometimes with videotapes, teachers are usually forced into more passive roles, unable to interact much with students until the movie is finished. Mrs. Chan also said certain students were able to understand a subject better when it is presented in a fresh, visual way. "Visual learners", she said, are especially drawn to videodisk instruction. But she cautioned that reading must remain part of the class work.

\section{REFERENCES}

[1] A. A. Kargar, "The efficiency of extensive reading project (ERP) in an Iranian EFL context," Theory and Practice in Language Studies, vol. 2 , no. 1 , pp. $165-169,2012$

[2] W. Tsang. "Comparing the effects of reading and writing on writing performance," Applied Linguistics, vol. 17, vol. 2, pp. 210-233, 1996.

[3] R. Fidalgo, M. Torrance, O. Ariasgundín, et al., "Comparison of reading-writing patterns and performance of students with and without reading difficulties," Psicothema, vol. 26, no. 4, pp. 442-448, 2014.

[4] N. Atwell, Coming to Know: Writing to Learn in the Intermediate Grades, Portsmouth, NH: Heinemann, 1989.

[5] L. Plakans, "Independent vs. Integrated writing tasks: A comparison of task representation," Tesol Quarterly, vol. 44, no. 1, pp. 185-194, 2010.

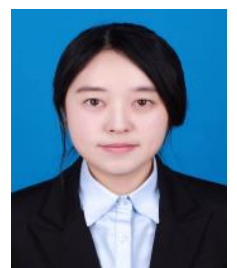

Shirley Shao was born on Dec. 16, 1991. She received the degree of mater of language studies in Hong Kong Baptist University in 2015. Shirley has worked as an English language teacher for three years in international schools and currently involves in TBLT field. Along with teaching, she also actively participates research programs. Recently she was prized for participating "investigating relationships between theory and practice in language teaching", lunched by Hong Kong University from 2016 to 2017. 